\section{The Dlk1 and Gt12 genes are linked and reciprocally imprinted}

\author{
Jennifer V. Schmidt, ${ }^{1,2}$ Paul G. Matteson, ${ }^{2}$ \\ Beverly K. Jones, Xiao-Juan Guan, \\ and Shirley $M$. Tilghman ${ }^{3}$ \\ Howard Hughes Medical Institute and Department \\ of Molecular Biology, Princeton University, Princeton, \\ New Jersey 08544 USA
}

\begin{abstract}
Genes subject to genomic imprinting exist in large chromosomal domains, probably reflecting coordinate regulation of the genes within a cluster. Such regulation has been demonstrated for the H19, Igf2, and Ins2 genes that share a bifunctional imprinting control region. We have identified the Dlk1 gene as a new imprinted gene that is paternally expressed. Furthermore, we show that $D I k 1$ is tightly linked to the maternally expressed GtI2 gene. $D l k 1$ and $G t 12$ are coexpressed and respond in a reciprocal manner to loss of DNA methylation. These genes are likely to represent a new example of coordinated imprinting of linked genes.
\end{abstract}

Received April 5, 2000; revised version accepted June 23, 2000.

Genomic imprinting refers to the differential expression of the two alleles of a gene that is dependent on their parent of origin. Imprinting was first demonstrated for the insulin-like growth factor 2 receptor $(I g f 2 r)$ and insulin-like growth factor 2 (Igf2) genes almost ten years ago (Barlow et al. 1991; DeChiara et al. 1991). Since then, $>30$ imprinted genes have been described in mammals (http://www.mgu.har.mrc.ac.uk/imprinting). Estimates of the total number of imprinted genes, based on the genomic regions of the mouse in which uniparental disomies display deleterious phenotypes, suggest there may be as many as 100 such genes.

The mechanisms that regulate imprinting are only beginning to be elucidated, but several general characteristics have emerged. First, the imprinting of a number of genes has been shown to rely on allele-specific DNA methylation that is established in the gametes and can act to either suppress or activate genes (Li et al. 1993). Second, a significant number of imprinted genes exist in large chromosomal clusters, suggesting coordinate control of linked genes. For example, a direct mechanistic link has been established for the mouse H19, Igf2, and Ins2 genes on chromosome 7, which use a single differ-

[Key words: Genomic imprinting; Dlk1; Gt12]

${ }^{1}$ Present address: Laboratory for Molecular Biology, Department of Biological Sciences, University of Illinois at Chicago, Chicago, Illinois 60607 USA.

${ }^{2}$ These authors contributed equally to this work.

${ }^{3}$ Corresponding author.

E-MAIL stilghman@molbio.princeton.edu; FAX (609) 258-3345. entially methylated cis-acting imprinting control element (Thorvaldson et al. 1998). Third, a majority of imprinted genes for which a function has been identified code for proteins involved in the control of embryonic growth (Tilghman 1999).

Given the role of imprinted genes in fetal growth it is not surprising that they are often expressed in the placenta, the primary tissue regulating nutrient transfer between mother and fetus. To identify new imprinted genes, we designed an allelic differential display strategy (Hagiwara et al. 1997) using placental mRNA derived from two closely related species of North American deer mice, Peromyscus maniculatus (BW) and Peromyscus polionotus (PO). These mice display a high degree of polymorphism (Vrana et al. 1998), making them useful for screens that depend on allelic differences.

We report here the paternal-specific expression of the Delta-like (DIk1) gene in both Peromyscus and the laboratory mouse genus Mus. We further show that Dlk1 is tightly linked in Mus and humans to Gt12, a gene encoding an untranslated RNA (Schuster-Gossler et al. 1998). Although it had been suggested that Gt12 was imprinted and expressed only from the paternal chromosome, we have determined that it is in fact maternally expressed. We demonstrate that the promoter of Gt12 but not Dlk1 is differentially methylated and that these genes respond to loss of CpG methylation in the DNA methyltransferase mouse mutant in a manner identical to that seen for $H 19$ and Igf2. Thus Dlk1 and Gtl2 define a new imprinted domain on mouse distal chromosome 12 that has striking structural and regulatory parallels to the wellstudied H19-Igf2 gene pair. This finding raises the possibility that imprinted gene clusters will have regulatory properties in common.

\section{Results}

We used multiple sets of differential display RT-PCR primers to amplify RNAs from late gestation placentae of the two Peromyscus parental strains and reciprocal $F_{1}$ crosses $(\mathrm{PO} \times \mathrm{BW}$ and $\mathrm{BW} \times \mathrm{PO})$. Given the imprinted expression of the $\mathrm{X}$ chromosome in placenta and maternal inheritance of mitochondria, maternal-specific bands could derive from expression of either X-linked or mitochondrial genes, in addition to maternally expressed imprinted genes. Therefore, we focused our initial analysis on paternal-specific bands, which could only be explained by imprinting.

\section{Dlk1 is imprinted in Peromyscus and Mus}

We focused on a differentially displayed band that was amplified from BW placental RNA but not from PO RNA, reflecting the fact that the primers uncovered a polymorphism between the two species (Fig. 1A). In reciprocal hybrids we observed a product in $\mathrm{PO} \times \mathrm{BW}$ RNA, but not BW $\times$ PO RNA, suggesting that the transcript is paternally expressed. To confirm this finding we developed a single strand conformational polymorphism 


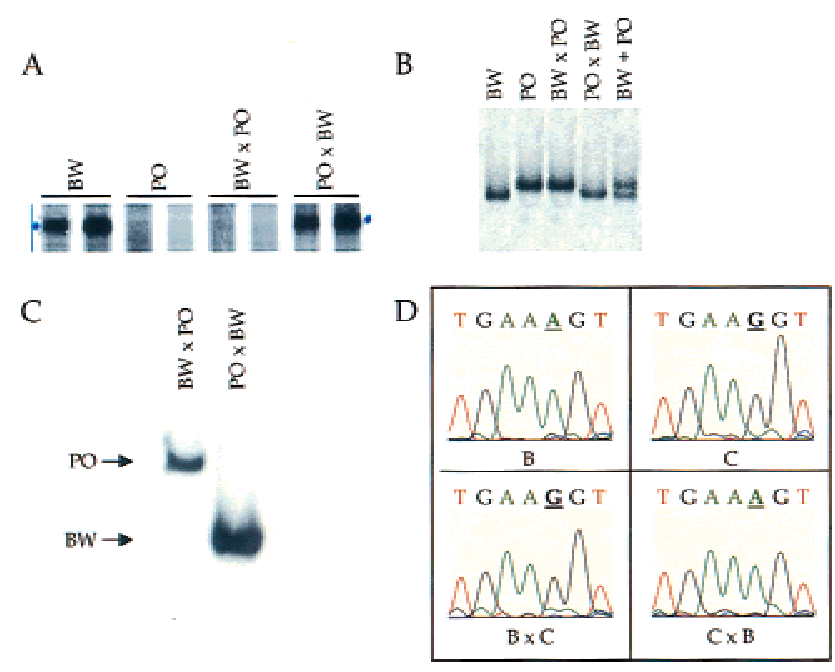

Figure 1. Imprinting of the Dlk1 gene in Peromyscus and Mus. (A) Differential display gel showing the polymorphism for Dlk1. (BW) P. maniculatus; (PO) P. polionotus; in the reciprocal crosses the female is listed first. (B) Dlk1 SSCP analysis for imprinting in Peromyscus placenta. RT-PCR was performed using E18.5 placental RNA from the BW and PO parental strains and reciprocal $\mathrm{F}_{1}$ crosses, as well as a 1:1 mixture of $\mathrm{BW}$ and $\mathrm{PO}$ RNAs (BW + PO). (C) Dlk1 SSCP analysis for imprinting in Peromyscus embryo. RT-PCR was performed using E18.5 embryo RNA from reciprocal $F_{1}$ crosses. The polymorphism is the same as that shown in $B$, however the gel was run longer to highlight the difference in migration. $(D)$ Imprinting of Dlk1 in Mus embryo. Direct sequencing was performed on RT-PCR products from E12.5 C57BL/6 (B) and Cast/Ei $(\mathrm{C})$ embryos and $\mathrm{F}_{1}$ offspring $(\mathrm{B} \times \mathrm{C}$ and $\mathrm{C} \times \mathrm{B})$. The polymorphic base is bold and underlined.

(SSCP) imprinting assay and verified that the gene was paternally expressed in Peromyscus placenta and embryo (Fig. 1B,C). We amplified, cloned, and sequenced the band and determined that it was the Peromyscus ortholog of the Dlk1 gene (GenBank accession no. AF272850; also referred to as Pref-1, FA-1, Scp-1, or $p$ G2) (Laborda et al. 1993; Smas and Sul 1993). This gene is a member of the Notch gene family and encodes a transmembrane protein widely expressed in the developing embryo. The Dlk1 extracellular domain can be proteolytically cleaved to generate a secreted protein that accumulates in the fetal and maternal circulation, as well as the amniotic fluid (Jensen et al. 1994; Bachmann et al. 1996). Dlk1 is induced by growth hormone and prolactin in the fetal and maternal pancreas, leading to increased proliferation of $\beta$-cells and an increase in insulin production (Carlsson et al. 1997). It has been implicated in the proliferation and differentiation of preadipocytes and stromal cells (Smas and Sul 1993; Moore et al. 1997).

To test whether Dlk1 was also paternally expressed in Mus we cloned and sequenced Dlk1 RT-PCR products derived from C57BL/6 (B) and Cast/Ei (C) placental RNAs. We identified a single nucleotide polymorphism in exon 5 of the Dlk1 gene, with the sequence TGAAAGT present in $\mathrm{B}$ animals and the sequence TGAAGGT present in C animals. Because this polymor- phism did not alter a restriction site, we used direct sequencing of RT-PCR products to analyze the allelic expression of the Dlk1 gene. RT-PCR was performed on embryo and placental RNA from the parental strains and reciprocal $\mathrm{F}_{1}$ crosses at embryonic day 12.5 (E12.5) and E18.5 (Fig. 1D; data not shown). Exclusive detection of the paternal allele established that Dlk1 is also paternally expressed in Mus embryo and placenta.

\section{Dlk1 maps to Mus chromosome 12}

The finding that Dlk 1 is paternally expressed in Mus was surprising, as the gene had been mapped previously to the X chromosome (Brady et al. 1997). The human DLK1 gene, on the other hand, maps to $14 \mathrm{q} 32.3$, in a region syntenic to distal mouse chromosome 12 (http://www. ncbi.nlm.nih.gov/genemap99). To resolve this disparity, we used an NdeI polymorphism at Dlk1 between BTBR and Mus spretus to type a $(\mathrm{BTBR} \times M$. spretus $) \times \mathrm{BTBR}$ backcross panel (Fig. 2A). The cosegregation of Dlk1 with Mit markers at the distal end of chromosome 12 confirmed that the Mus Dlk1 gene maps to chromosome 12 (Fig. 2A).

\section{Dlk1 is linked to the Gt12 gene}

The localization of Dlk1 to the distal end of Mus chromosome 12 suggested that it might lie near another re-

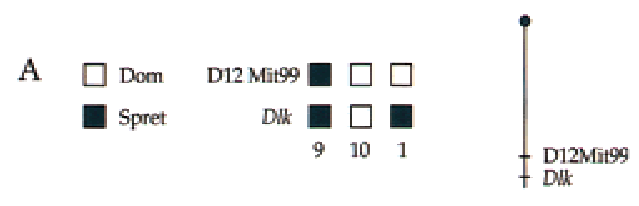

B
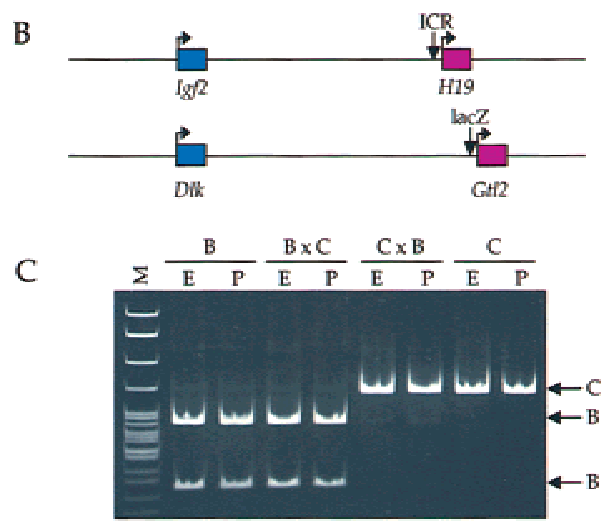

Figure 2. Linkage of the Dlk1 and Gt12 genes on Mus chromosome 12 and maternal expression of Gt12. (A) Genotypes of 20 $(\mathrm{BTBR} \times M$. spretus $) \times$ BTBR backcross animals typed for D12Mit99 and Dlk1. The mapping places Dlk1 $1 \mathrm{~cm}$ distal to D12Mit99. (B) Genomic organization of Dlk1 and Gt12 genes compared to H19 and Igf2. Blue boxes denote paternally expressed genes and pink boxes denote maternally expressed genes. The arrows indicate the ICR that regulates imprinting of $H 19$ and Igf2 and the insertion site of the lacZ gene trap vector in the Gt12 ${ }^{1 a c Z}$ mice (lacZ). (C) RT-PCR analysis for Mus Gt12 imprinting. RT-PCR products from E12.5 C57BL/6 (B) and Cast/Ei $(\mathrm{C})$ and $\mathrm{F}_{1}$ embryo $(\mathrm{E})$ and placenta $(\mathrm{P})$ were digested with $S f C I$ and analyzed by acrylamide gel electrophoresis. 
cently described imprinted gene, Gt12. Gt12 was identified in the analysis of a lacZ insertional mutation in an embryonic stem cell gene-trap screen (Schuster-Gossler et al. 1996). Paternal inheritance of the lacZ transgene gave a proportional dwarfism phenotype, implying that a paternally expressed locus affecting growth was disrupted. The Gtl2 transcript is widely expressed during development but does not appear to encode a protein, as it is inefficiently spliced and contains no significant open reading frames (Schuster-Gossler et al. 1998). We examined the potential linkage of Dlk1 and Gt12 by screening a mouse bacterial artificial chromosome (BAC) library with probes for each gene. A single BAC was identified that hybridized to both probes (data not shown). Pulsed-field gel analysis of the BAC demonstrated that the two genes are transcribed in the same orientation and their promoters lie $\sim 120 \mathrm{~kb}$ apart (Fig. 2B). Sequence analysis of the syntenic region of human chromosome 14 covering the DLK1 and GTL2 genes and their intergenic region (GenBank accession nos. AL132711 and AL117190) verified that the linkage and transcriptional orientation of the genes is conserved in humans.

\section{Gt12 is maternally expressed in Mus}

Based on the reduced level of Gt12 expression in parthenogenetic embryos, it was proposed that the Gt12 gene was paternally expressed (Schuster-Gossler et al. 1998). In light of the linkage between Dlk1 and Gt12 we investigated the imprinting status of Gt12 more rigorously. The C57BL/6 and Cast/Ei alleles of Gt12 were sequenced and a single nucleotide polymorphism was identified in the 3' end of the Gt12 transcript. This polymorphism alters an $S f c$ I restriction site that is present in the B allele but absent in the $\mathrm{C}$ allele. Restriction enzyme digestion of RT-PCR products from embryo and placenta at E12.5 and E18.5 of reciprocal crosses between B and C showed that, contrary to the previous report, Gtl2 is expressed exclusively from the maternal allele in Mus (Fig. 2C; data not shown).

\section{Dlk1 and Gt12 are coexpressed during development}

The reciprocal imprinting of Dlk1, a paternally expressed growth regulator and Gt12, a maternally expressed noncoding RNA, is highly reminiscent of the H19-Igf2 gene pair on mouse chromosome 7 (Fig. 2B). H19 and Igf2 were first suspected to be coordinately regulated based on their linkage and similar patterns of expression during embryogenesis. This coexpression was later demonstrated to be the result of shared enhancers located $3^{\prime}$ to the $H 19$ gene (Leighton et al. 1995b). Dlk1 has been reported to be widely expressed in the embryo including preadipocytes, placental stromal cells, the adrenal gland, pituitary, and the anlage of the fetal pancreas (Jensen et al. 1993; Laborda et al. 1993; Smas and Sul 1993). Gt12 is likewise widely expressed throughout development, with high levels of expression in the paraxial mesoderm, the developing central nervous system, and the epithelia of the kidney, pancreas, and salivary gland (Schuster-Gossler et al. 1998).
To examine in more detail the potential for coordinate regulation of Dlk1 and Gt12, we performed Northern analysis at various stages of Mus development (Fig. 3A). This assay showed that both genes are activated between E7 and E11 in embryos. It has been reported previously, based on in situ hybridization analysis, that Gt12 is expressed throughout early embryogenesis, from the onecell stage onward (Schuster-Gossler et al. 1998). Our Northern analysis, however, was unable to detect expression of Gt12 RNA earlier than day E11 even on longer exposure.

In adults, DIk 1 is expressed primarily in the stromal and $\beta$ cells of the pancreas, the bone marrow, and adrenal gland (Laborda et al. 1993; Jensen et al. 1994; Moore et al. 1997; Bauer et al. 1998). Based on Northern analysis of adult mouse tissues, we show that Dlk1 and Gt12 are coexpressed, primarily in the pituitary and adrenal gland, but not in brain, where only Gt12 RNA is detected (Fig. 3B). In addition, semiquantitative RT-PCR of Mus adult pancreas RNA showed both Dlk1 and Gt12 to be highly expressed in this tissue (data not shown).

\section{Expression of Dlk1 and Gtl2 is dependent on DNA methylation}

The coregulated H19 and Igf2 genes have been shown to display reciprocal alterations in expression on the loss of DNA methylation. The DNA methyltransferase mutant mouse $\left(D n m t^{-/-}\right)$, which lacks the maintenance DNA methyltransferase, is lethal shortly after day E9.5. At E9.5, on the paternal chromosome $H 19$ expression is upregulated in the absence of DNA methylation whereas the Igf2 gene is silenced (Li et al. 1993). It has been proposed that the loss of DNA methylation at the single imprinting control region (ICR), located between -2 and $-4 \mathrm{~kb}$ relative to the start of $H 19$ transcription, activates the adjacent $H 19$ gene on the paternal chromosome,

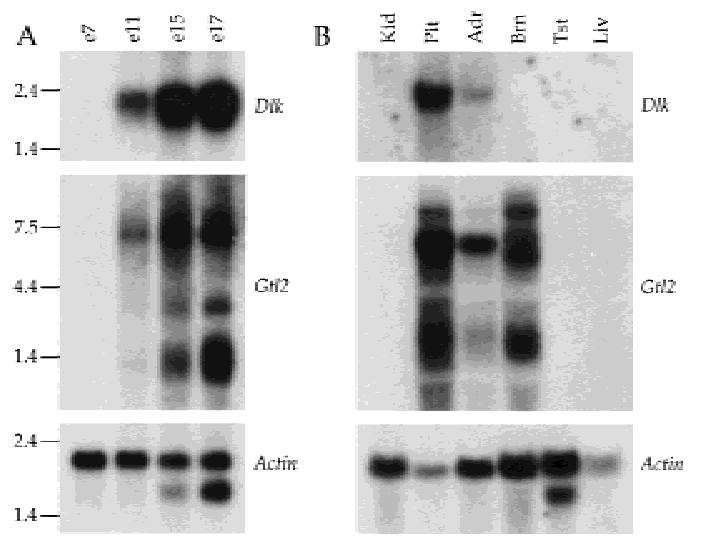

Figure 3. Coordinate expression of the Dlk1 and Gt12 genes in Mus embryo and adult. (A) Northern analysis for Dlk1 and Gt12 RNA in Mus embryos at various stages of development. $(B)$ Northern analysis for Dlk1 and Gt12 RNA in adult Mus tissues. The lane designations, left to right, are kidney, pituitary, adrenal, brain, testis, and liver. For both blots the expression of the $\beta$-actin gene is included as a loading control. The positions of RNA size markers are indicated. 


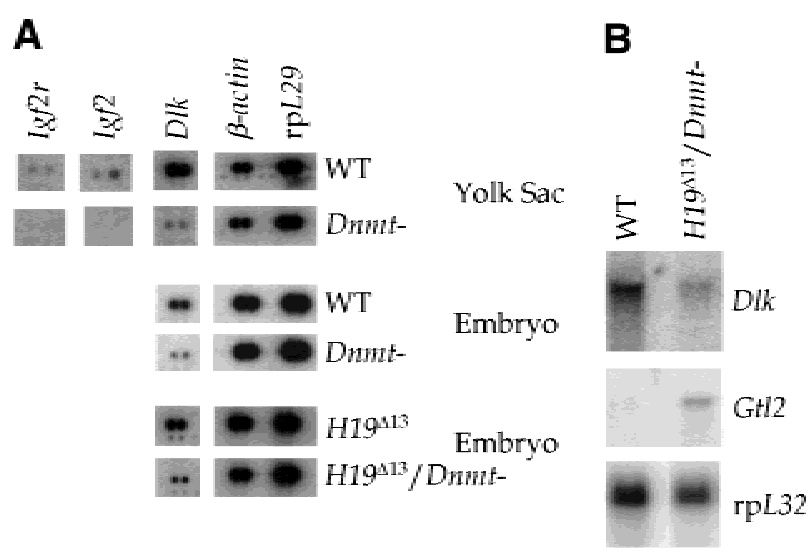

Figure 4. Altered expression of the Dlk1 and Gt12 genes in $D n m t^{-/-}\left(D n m t^{S}\right)$ embryos. (A) Hybridization of wild-type (WT), $D n m t^{-/-}$, and Dnmt $t^{-/-} / H 19^{\Delta 13}$ RNA to the Atlas cDNA expression microarray containing the genes indicated. $(B)$ Northern analysis for Dlk1 and Gt12 expression in wild-type and Dnmt ${ }^{-/-}$ $H 19^{\Delta 13}$ embryos. Expression of the $\operatorname{rpL32}$ gene is included as a loading control.

which is normally heavily methylated. The loss of Igf2 expression, in contrast, has been proposed to be an indirect consequence of the activation of $H 19$ transcription (Li et al. 1993).

To gain a better understanding of the mechanism regulating the imprinting of Dlk1 and Gt12, we examined the expression of Dlk1 and Gt12 in Dnmt ${ }^{-/-}$embryo and yolk sac of E9.5 embryos $\left(D n m t^{s}\right)$. Our initial analysis made use of a cDNA microarray containing 588 full-length cDNA clones that included Dlk1, as well as the imprinted Igf2 and Igf2r genes (Atlas cDNA microarray, Clontech). Duplicate microarray blots were hybridized with embryo and yolk sac RNA from E9.5 wild-type and $D n m t^{-/-}$animals. The Dlk1 gene was highly expressed in yolk sac of the control animals and significantly down regulated in the $D n m t^{-/-}$animals (Fig. 4A). Dlk1 expression was also decreased in $D n m t^{-/-}$embryo RNA. The response of Dlk1 was very similar to that of Igf2 and Igf2r, both of which are repressed in the absence of DNA methylation (Fig. 4A) (Li et al. 1993). As the amount of RNA obtained from the E9.5 $\mathrm{Dnmt}^{-/-}$embryos is very small we took advantage of tissue available from animals deficient in both Dnmt and H19 $\left(H 19^{\Delta 13}\right)$ to perform Northern analysis. This $H 19$ mutation results in a loss of imprinting at the adjacent Igf2 and Ins2 genes (Leighton et al. 1995a), but it had no effect on the expression of Dlk1 in either $\mathrm{Dnmt}^{+/+}$or mutant animals (Fig. 4A). Northern analysis of RNA from wild-type and $\mathrm{H} 9^{\Delta 13}$ / $D n m t^{-/-}$embryos confirmed the microarray results for Dlk1 and showed that the level of expression was $\sim 30 \%$ of wild type (Fig. 4B). Moreover, by reprobing the same blot, Gt12 RNA was only detectable in the absence of DNA methylation (Fig. 4B).

These results prompted us to examine Dlk1 and Gt12 for regions of allele-specific methylation. The first exons of both genes have a high CpG content that is conserved in the human DLK1 and GTL2 genes. We used Southern blotting with methylation sensitive restriction enzymes to examine the methylation status of the 5' ends of Dlk1 and Gt12 in the mouse. The promoter and first exon of Gtl2 showed striking differential methylation, based on cleavage by HpaII, consistent with allele-specific methylation (Fig. 5A). Surprisingly, placental DNA showed far less methylation, consistent with the known global undermethylation of placental DNA. In spite of this lack of methylation, however, Gtl2 is tightly imprinted in the placenta. In contrast to Gtl2, the Dlk1 promoter and first exon were found to be unmethylated on both alleles (Fig. 5B).

\section{Discussion}

Dlk1 and Gtl2 define a new cluster of imprinted genes on distal mouse chromosome 12, a region predicted to contain imprinted genes from the phenotypes of uniparental chromosomal duplications in mouse and human. Maternal uniparental disomy for distal mouse chromosome 12 results in late embryonic or early neonatal lethality with reduced growth and paternal inheritance of the disomy results in embryonic lethality with enhanced growth (http://www.mgu.har.mrc.ac.uk/imprinting/imptables. html). Uniparental disomy involving growth effects has also been reported in humans for the syntenic region of chromosome 14 (Temple et al. 1991; Wang et al. 1991).

The Gt $12^{\text {lac } Z}$ gene trap, which integrated just upstream of Gt12, resulted in growth retardation when inherited paternally (Schuster-Gossler et al. 1998). Although it was originally proposed that the phenotype was caused by a decrease in Gt12 expression, no decrease was observed in either maternal or paternal heterozygotes, although homozygous mutant embryos expressed reduced levels of RNA. Given our finding of paternal-specific expression of Dlk1 and its established role in insulin control (Carls-

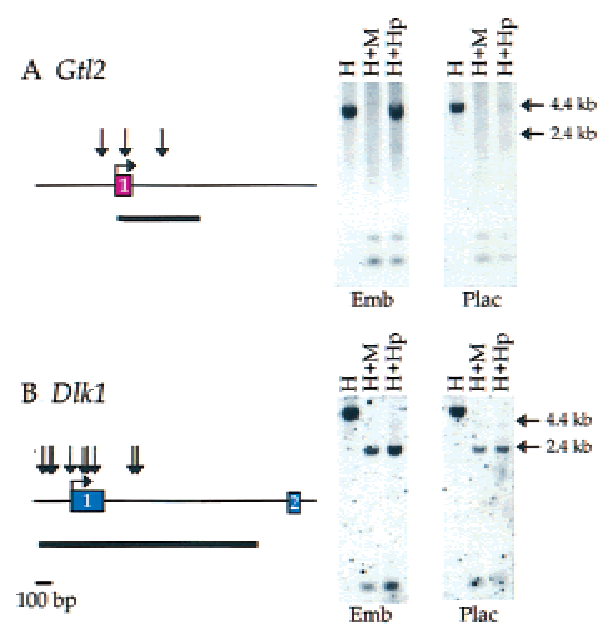

Figure 5. Methylation analysis of the Gt12 and Dlk1 promoter regions. (A) Methylation analysis of the Gt12 promoter and first exon by Southern blotting using HincII $(\mathrm{H})$, HincII + MspI $(\mathrm{H}+\mathrm{M})$ or HincII + HpaII $(\mathrm{H}+\mathrm{Hp})$. The location of the MspI/ HpaII sites are indicated by the arrows and the probe by the dark line. Molecular DNA markers are indicated to the right of the gel. (B) Methylation analysis of the Dlk1 promoter and first exon. Abbreviations as in $A$. 
son et al. 1997; Efstratiadis 1998), it now seems more likely that deregulation in Dlk1 expression underlies the Gt12 lacz growth phenotype. If so, then the gene trap may have disrupted an element controlling the expression of Dlk1, such as an enhancer or imprinting control element that is required for proper expression of both genes.

The genomic organization, imprinting behavior, methylation status and coexpression of DIk1 and Gt12 are highly reminiscent of $H 19$ and Igf2. Both clusters encode a maternally expressed untranslated RNA and a paternally expressed fetal growth factor that are coexpressed during embryogenesis. Thus Dlk1 is added to the list of paternally expressed imprinted genes that are involved in promoting embryonic growth and supports the proposal that imprinting arose to regulate placental growth (Haig 1992). Furthermore Dlk1 is positively regulated by DNA methylation, like Igf2, whereas $H 19$ and GtI2 are negatively regulated, based on our analysis of $\mathrm{Dnmt}^{-/-}$ embryos. Another similarity extends to the imprinting of Dlk1 in Peromyscus hybrids. In previous work we showed that many paternally expressed genes were deregulated in $\mathrm{PO} \times \mathrm{BW}$ hybrids, which exhibit dramatic growth dysmorphologies of the placenta and embryo (Vrana et al. 1998). One exception to this rule was Igf2, whose imprinting was maintained. The maintenance of Dlk1 imprinting in these hybrids as well further implies that the two genes may be regulated by similar mechanisms.

DNA methylation has been shown to be necessary for the proper expression of all imprinted genes with the exception of Mash2 (Caspary et al. 1998; Tanaka et al. 1999). Indeed, methylation is believed to represent the primary imprinting mark. Imprinted genes can be divided into two classes based on whether they are activated or repressed by the loss of DNA methylation. It has been proposed that this classification reflects the organization of imprinted genes into clusters in which a single ICR mediates the imprinting of multiple genes (Barlow 1997; Tilghman 1999). In this model, the gene that is adjacent to the ICR will be directly silenced by the methylation of the ICR itself. This applies to H19, as well as to the paternally expressed Snrpn gene and the maternally expressed antisense transcript at the Igf2r locus (Shemer et al. 1997; Wutz et al. 1997). Loss of DNA methylation, then, results in activation of the normally silent allele of these genes, with a concomitant increase in expression levels. Gt12 appears to be in this class, based on its differential methylation and activation in $D n \mathrm{mt}^{-/-}$mice.

The silencing of genes such as Igf2 and Igf2r by demethylation is believed to be more indirect. In the case of Igf2, experimental evidence points to a chromatin insulator within the unmethylated ICR that is required to block Igf2 expression on the maternal chromosome (Bell and Felsenfeld 2000; Hark et al. 2000). At this locus, the ICR lies between the Igf2 gene and the enhancers it shares with H19 (Fig. 2B). Two groups have recently shown that the unmethylated ICR binds CTCF, a Zn finger-containing protein that binds DNA in a methylation-sensitive manner and has been implicated in insu- lator function in other vertebrates (Bell et al. 1999; Bell and Felsenfeld 2000; Hark et al. 2000). It is proposed that when the paternal ICR is demethylated in $D n m t^{-1-}$ embryos, an insulator forms inappropriately on the ICR and blocks Igf2 expression. The inhibition of Dlk1 expression in $D n m t^{-1-}$ embryos, coupled with its lack of differential methylation, argues that it is in this second class of genes. The similarities we have described between H19-Igf2 and Dlk1-Gt12 suggest that general mechanisms involved in imprinting may be revealed by a comparative analysis of these two loci.

\section{Materials and methods}

\section{DNA and RNA analysis}

RNA for differential display was isolated by the guanidinium isothiocyanate method followed by $\mathrm{CsCl}$ centrifugation; RNA for Northern analysis was prepared by lithium chloride-urea precipitation. The mouse embryo Northern was purchased from Clontech. RNAs for the adult mouse Northern were separated on a formaldehyde-MES agarose gel, transferred to Hybond N+and hybridized with Express-Hyb (Clontech). Washes were $2 \times 15 \mathrm{~min}$ in $2 \times \mathrm{SSC} / 0.1 \%$ SDS at room temperature, followed by $2 \times 30$ min in $0.1 \times \mathrm{SSC} / 0.1 \% \mathrm{SDS}$ at $50^{\circ} \mathrm{C}$. The microarrays were analyzed as detailed by the manufacturer (Clontech). For Southern blotting and methylation analysis, genomic DNAs were separated on $1 \times$ TAE agarose gels and transferred to Hybond $\mathrm{N}+$ (Amersham). Hybridization was carried out at $65^{\circ} \mathrm{C}$ in $5 \times$ SSPE, $5 \times$ Denhardt's solution, and $0.5 \%$ SDS. Washes were as for Northern blots except all were at $65^{\circ} \mathrm{C}$. The probe for the Gt12 methylation blot was a 532-bp SacI-XhoI fragment that recognizes a 4.3-kb HincII genomic fragment containing exon 1, and the probe for Dlk1 methylation was a 1.6-kb NotI-NcoI fragment that recognizes a 4.5-kb HincII genomic fragment containing exons 1 and 2.

\section{Differential display screen}

Placental tissue from the Peromyscus parental strains and reciprocal $\mathrm{F}_{1}$ crosses were isolated between E14.5 and E16.5. The differential display reactions were carried out using primers from the Gene Hunter RNA image kit and a modification of the basic protocol (Liang and Pardee 1992). Cycling parameters were 4 cycles of $\left(94^{\circ} \mathrm{C}\right.$ for $45 \mathrm{sec}, 37^{\circ} \mathrm{C}-42^{\circ} \mathrm{C}$ over $2.5 \mathrm{~min}, 72^{\circ} \mathrm{C}$ for $\left.30 \mathrm{sec}\right)$ and $35 \mathrm{cycles}$ of $\left(94^{\circ} \mathrm{C}\right.$ for $45 \mathrm{sec}, 42^{\circ} \mathrm{C}$ for $2.5 \mathrm{~min}, 72^{\circ} \mathrm{C}$ for $30 \mathrm{sec}$ ) and $72^{\circ} \mathrm{C}$ for $10 \mathrm{~min}$. Reactions were analyzed on $1 \times \mathrm{TBE}, 5 \%$ acrylamide gels and exposed to film overnight. Bands were excised from the gel and reamplification carried out using the cycling parameters $94^{\circ} \mathrm{C}$ for $45 \mathrm{sec}, 42^{\circ} \mathrm{C}$ for $2.5 \mathrm{~min}, 72^{\circ} \mathrm{C}$ for $30 \mathrm{sec}$ for $25-30$ cycles, $72^{\circ} \mathrm{C}$ for $10 \mathrm{~min}$.

\section{Chromosomal mapping of the Dlk1 gene}

Dlk1 linkage to Mus chromosome 12 was determined by typing 20 $($ BTBR $\times$ M. spretus $) \times$ BTBR DNAs using PCR with the D12Mit99 primer pair. The same DNAs were also digested with NdeI and analyzed by Southern blotting using a 1.5-kb C57BL/6 Dlk1 cDNA fragment as a probe.

\section{SSCP analysis}

Placental tissue from the Peromyscus parental strains and reciprocal $F_{1}$ crosses were isolated at day E18.5. The RT-PCR reactions were carried out using $\left[{ }^{33} \mathrm{P}\right] \mathrm{dCTP}$. Samples were denatured in $95 \%$ formamide $/ 10 \mathrm{~mm}$ $\mathrm{NaOH}$ at $94^{\circ} \mathrm{C}$ for $5 \mathrm{~min}$ and the bands resolved on a $0.5 \times \mathrm{MDE}$ (FMC BioProducts), 0.6× TBE gel. The Dlk1 primers were 5'-TGACCACCTTCAACAAGGAGGC- $3^{\prime}$ and 5'-GTAGCATGGCACACAGCAACAC-3', which amplify a 110-bp fragment within exon 5 .

Mus imprinting assays

Mus Dlk1 was amplified by RT-PCR using primers (5'-CTGGCGGTCAATATCATCTTCC-3') and (5'-GAGGAAGGGGTTCTTAGATAGCG-3'), which amplify a 288-bp fragment of exon 5. PCR products were sequenced directly and chromatograms analyzed for nucleotide 1258 relative to the transcriptional start. Mus Gt12 was amplified by RT-PCR using primers 5'-GCCAAAGCCATCATCTGGAATC-3' and 5'-CACAGATGTAGACTCAACAGTGAAG-3', which amplify a 306-bp fragment spanning exons 8 and 9. PCR products were digested with $S f c I$, which 
cuts at nucleotide 1570 relative to the Gt12 transcriptional start, and analyzed on a $7.5 \%$ acrylamide gel. In all imprinting analyses control reactions in the absence of reverse transcriptase were negative. In addition artificial mixtures of the two parental RNAs were amplified to ensure that there was no bias between the two alleles. In the case of Dlk1, these mixtures were also sequenced to verify no bias in the sequencing procedure. Additionally, all imprinting analyses were also verified on genomic DNA from the respective $F_{1}$ crosses and showed the equivalent detection of both parental alleles.

\section{Acknowledgments}

The authors wish to thank the members of the Tilghman laboratory for comments on the manuscript, Paul Vrana for many discussions on the project, and Robert Ingram for assistance with methylation analysis. This work was supported by a Jane Coffin Childs postdoctoral fellowship (J.V.S.) and a grant from the National Institute of General Medical Sciences (S.M.T.). S.M.T. is an investigator of the Howard Hughes Medical Institute.

The publication costs of this article were defrayed in part by payment of page charges. This article must therefore be hereby marked "advertisement" in accordance with 18 USC section 1734 solely to indicate this fact.

\section{Note added in proof}

Miyoshi et al. (2000) have also recently shown that the Gtl2 gene is maternally expressed in mouse and human.

\section{References}

Bachmann, E., Krogh, T.N., Hojrup, P., Skjodt, K., and Teisner, B. 1996. Mouse fetal antigen 1 (mFAl), the circulating gene product of mdlk, pref-1 and SCP-1: Isolation, characterization and biology. J. Reprod. Fertil. 107: 279-285.

Barlow, D.P., Stoger, R., Herrmann, B.G., Saito, K., and Schweifer, N 1991. The mouse insulin-like growth factor type-2 receptor is imprinted and closely linked to the Tme locus. Nature 349: 84-87.

Barlow, D.P. 1997. Competition-a common motif for the imprinting mechanism? EMBO J. 16: 6899-6905.

Bauer, S.R., Ruiz-Hidalgo, M.J., Rudikoff, E.K., Goldstein, J., and Laborda, J. 1998. Modulated expression of the epidermal growth factor-like homeotic protein dlk influences stromal-cell-pre-B-cell interactions, stromal cell adipogenesis, and pre-B-cell interleukin-7 requirements Mol. Cell. Biol. 18: 5247-5255.

Bell, A.C. and Felsenfeld, G. 2000. Methylation of a CTCF-dependent boundary controls imprinted expression of the Igf2 gene. Nature 405: 482-485

Bell, A.C., West, A.G., and Felsenfeld, G. 1999. The protein CTCF is required for the enhancer blocking activity of vertebrate insulators. Cell 98: 387-396,

Brady, K.P., Rowe, L.B., Her, H., Stevens, T.J., Eppig, J., Sussman, D.J., Sikela, J., and Beier, D.R. 1997. Genetic mapping of 262 loci derived from expressed sequences in a murine interspecific cross using single-strand conformational polymorphism analysis. Genome Res. 7: 1085-1093.

Carlsson, C., Tornehave, D., Lindberg, K., Galante, P., Billestrup, N., Michelsen, B., Larsson, L.I., and Nielsen, J.H. 1997. Growth hormone and prolactin stimulate the expression of rat preadipocyte factor-1/ delta-like protein in pancreatic islets: Molecular cloning and expression pattern during development and growth of the endocrine pancreas. Endocrinology 138: 3940-3948.

Caspary, T., Cleary, M.A., Baker, C.C., Guan, X.-J., and Tilghman, S.M. 1998. Multiple mechanisms regulate imprinting of the mouse distal chromosome 7 gene cluster. Mol. Cell. Biol. 18: 3466-3474.

DeChiara, T.M., Robertson, E.J., and Efstratiadis, A. 1991. Parental imprinting of the mouse insulin-like growth factor II gene. Cell 64: 849-859.

Efstratiadis, A. 1998. Genetics of mouse growth. Int. J. Dev. Biol. 42: 955-976

Hagiwara, Y., Hirai, M., Nishiyama, K., Kanazawa, I., Ueda, T., Sakaki, Y., and Ito, T. 1997. Screening for imprinted genes by allelic message display: Identification of a paternally expressed gene impact on mouse chromosome 18. Proc. Natl. Acad. Sci. 94: 9249-9254.

Haig, D. 1992. Genomic imprinting and the theory of parent-offspring conflict. Sem. Dev. Biol. 3: 153-160.
Hark, A.T., Schoenherr, C.J., Katz, D.J., Ingram, R.S., Levorse, J.M., and Tilghman, S.M. 2000. CTCF mediates methylation-sensitive enhancer blocking activity at the H19/Igf2 locus. Nature 405: 486489.

Jensen, C.H., Krogh, T.N., Hojrup, P., Clausen, P.P., Skjodt, K., Larsson, L.I., Enghild, J.J., and Teisner, B. 1994. Protein structure of fetal antigen 1 (FA1). A novel circulating human epidermal-growth-factorlike protein expressed in neuroendocrine tumors and its relation to the gene products of Dlk1 and $p G 2$. Eur. J. Biochem. 225: 83-92.

Jensen, C.H., Teisner, B., Hoirup, P., Rasmussen, H.B., Madsen, O.D. Nielsen, B., and Skjodt, K. 1993. Studies on the isolation, structural analysis and tissue localization of fetal antigen 1 and its relation to a human adrenal-specific cDNA, $p$ G2. Hum. Reprod. 8: 635-641.

Laborda, J., Sausville, E.A., Hoffman, T., and Notario, V. 1993. Dlk1, a putative mammalian homeotic gene differentially expressed in small cell lung carcinoma and neuroendocrine tumor cell line. I. Biol. Chem. 268: 3817-3820.

Leighton, P.A., Ingram, R.S., Eggenschwiler, J., Efstratiadis, A., and Tilghman, S.M. 1995a. Disruption of imprinting caused by deletion of the $H 19$ gene region in mice. Nature 375: 34-39.

Leighton, P.A., Saam, J.R., Ingram, R.S., Stewart, C.L., and Tilghman, S.M. 1995b. An enhancer deletion affects both H19 and Igf2 expression. Genes \& Dev. 9: 2079-2089.

Li, E., Beard, C., and Jaenisch, R. 1993. The role of DNA methylation in genomic imprinting. Nature 366: 362-365.

Liang, P. and Pardee, A.B. 1992. Differential display of eukaryotic messenger RNA by means of the polymerase chain reaction. Science 257: 967-971.

Miyoshi, N., Wagatsuma, H., Wakana, S., Shiroishi, T., Nomura, M., Aisaka, K., Kohda, K., Surani, M.A., Kaneko-Ishino, T., and Ishino, F. 2000. Identification of an imprinted gene, Meg3/Gt12 and its human homologue $M E G 3$, first mapped on mouse distal chromosome 12 and human chromosome 14q. Genes Cells 5: 211-220.

Moore, K.A., Pytowski, B., Witte, L., Hicklin, D., and Lemischka, I.R. 1997. Hematopoietic activity of a stromal cell transmembrane protein containing epidermal growth factor-like repeat motifs. Proc. Nat1. Acad. Sci. 94: 4011-4016.

Schuster-Gossler, K., Bilinski, P., Sado, T., Ferguson-Smith, A., and Gossler, A. 1998. The mouse Gt12 gene is differentially expressed during embryonic development, encodes multiple alternatively spliced transcripts, and may act as an RNA. Dev. Dyn. 212: 214-228.

Schuster-Gossler, K., Simon-Chazottes, D., Guenet, J.-L., Zachgo, J., and Gossler, A. 1996. Gt12lacZ, an insertional mutation on mouse chromosome 12 with parental origin-dependent phenotype. Mamm. Genome 7: 20-24.

Shemer, R., Birger, Y., Riggs, A.D., and Razin, A. 1997. Structure of the imprinted mouse Snrpn gene and establishment of its parental-specific methylation pattern. Proc. Nat. Acad. Sci. 94: 10267-10272.

Smas, C.M. and Sul, H.S. 1993. Pref-1, a protein containing EGF-like repeats, inhibits adipocyte differentiation. Cell 73: 725-734.

Tanaka, M., Puchyr, M., Gertsenstein, M., Harpal, K., Jaenisch, R., Rossant, J., and Nagy, A. 1999. Parental origin-specific expression of Mash2 is established at the time of implantation with its imprinting mechanism highly resistant to genome-wide demethylation. Mech. Dev. 87: 129-142.

Temple, I.K., Cockwell, A., Hassold, T., Pettay, D., and Jacobs, P. 1991. Maternal uniparental disomy for chromosome 14. J. Med. Genet. 28: 511-514.

Thorvaldson, J.L., Duran, K.L., and Bartolomei, M.S. 1998. Deletion of the $H 19$ differentially methylated domain results in loss of imprinted expression of H19 and Igf2. Genes \& Dev. 12: 3693-3702.

Tilghman, S.M. 1999. The sins of the fathers and mothers: Genomic imprinting in mammalian development. Cell 96: 185-193.

Vrana, P.B., Guan, X.-J., Ingram, R.S., and Tilghman, S.M. 1998. Genomic imprinting is disrupted in interspecific Peromyscus hybrids. Nature Genet. 20: 362-365.

Wang, J.-C.C., Passage, M.B., Yen, P.H., Shapiro, L.J., and Mohandas, T.K. 1991. Uniparental heterodisomy for chromosome 14 in a phenotypically abnormal familial balanced 13/14 Robertsonian translocation carrier. Am. J. Hum. Genet. 48: 1069-1074.

Wutz, A., Smrzka, O.W., Schweifer, N., Schellander, K., Wagner, E.F., and Barlow, D.P. 1997. Imprinted expression of the Igf2r gene depends on an intronic CpG island. Nature 389: 745-749. 


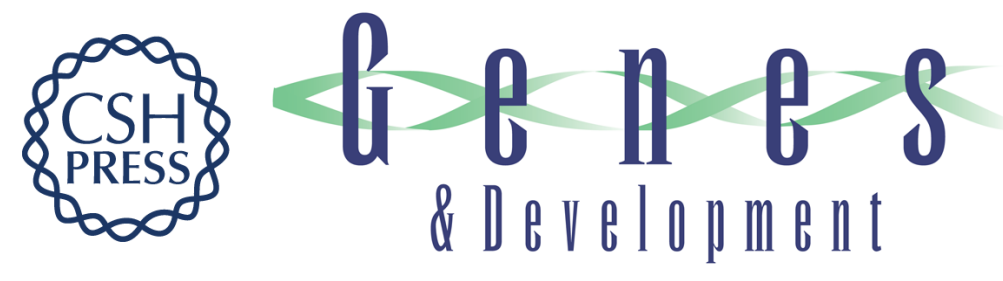

\section{The DIk1 and Gt/2 genes are linked and reciprocally imprinted}

Jennifer V. Schmidt, Paul G. Matteson, Beverly K. Jones, et al.

Genes Dev. 2000, 14:

Access the most recent version at doi:10.1101/gad.14.16.1997

References This article cites 33 articles, 13 of which can be accessed free at: http://genesdev.cshlp.org/content/14/16/1997.full.html\#ref-list-1

License

Email Alerting Receive free email alerts when new articles cite this article - sign up in the box at the top Service right corner of the article or click here.

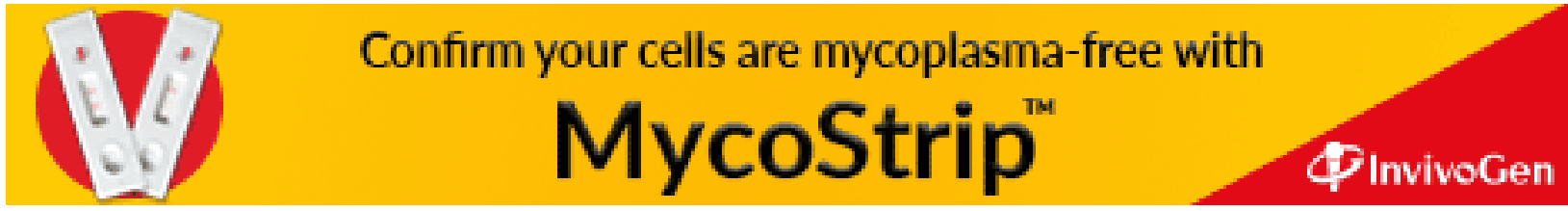

